\title{
Practical stepwise approach to rhythm disturbances in congenital heart diseases
}

June Huh, M.D., Ph.D.

Department of Pediatrics, Cardiac and Vascular Center, Samsung Medical Center, Sungkyunkwan University School of Medicine, Seoul, Korea

Received: 14 May 2010, Accepted: 19 May 2010

Corresponding Author: June Huh, MD., Ph.D.

Division of Pediatric Cardiology, Department of Pediatrics, Cardiac and Vascular Center, Samsung Medical Center, Sungkyunkwan University School of Medicine, 50 Irwon-dong, Gangnam-gu, Seoul 135-710, Korea

Tel: +82-2-3410-3539, Fax: +82-2-3410-0043

E-mail: herzhuh@skku.edu

Copyright (C) 2010 by The Korean Pediatric Society
Patients with congenital heart diseases (CHD) are confronted with early- and late-onset complications, such as conduction disorders, arrhythmias, myocardial dysfunction, altered coronary flow, and ischemia, throughout their lifetime despite successful hemodynamic and/or anatomical correction. Rhythm disturbance is a well-known and increasingly frequent cause of morbidity and mortality in patients with CHD. Predisposing factors to rhythm disturbances include underlying cardiac defects, hemodynamic changes as part of the natural history, surgical repair and related scarring, and residual hemodynamic abnormalities. Acquired factors such as aging, hypertension, diabetes, obesity, and others may also contribute to arrhythmogenesis in CHD. The first step in evaluating arrhythmias in CHD is to understand the complex anatomy and to find predisposing factors and hemodynamic abnormalities. A practical stepwise approach can lead to diagnosis and prompt appropriate interventions. Electrophysiological assessment and management should be done with integrated care of the underlying heart defects and hemodynamic abnormalities. Catheter ablation and arrhythmia surgery have been increasingly applied, showing increasing success rates with technological advancement despite complicated arrhythmia circuits in complex anatomy and the difficulty of access. Correction of residual hemodynamic abnormalities may be critical in the treatment of arrhythmia in patients with CHD.

Key words: Congenital heart defects, Cardiac arrhythmia, Diagnosis, Risk factors

This is an open-access article distributed under the terms of the Creative Commons Attribution Non-Commercial License (http://creativecommons.org/licenses/by$\mathrm{nc} / 3.0 /$ ) which permits unrestricted non-commercial use, distribution, and reproduction in any medium, provided the original work is properly cited.

\section{Introduction}

Survival of patients having congenital heart disease (CHD) has remarkably improved with rapid advances in medical and surgical treatments. This has brought a new population of adult CHD cases and increasing incidence of late-onset complications, such as heart failure or rhythm disturbances, during the patients' lifetime regardless of successful hemodynamic and anatomical correction.

Rhythm disturbances in CHD are well-known complications that could occur throughout lifetime and may be life threatening. They can cause serious hemodynamic compromise and sudden cardiac death in patients with CHD. Individuals with CHD may 
have a different conduction system from those with a structurally normal heart due to errors in embryologic development. Arrhythmias in CHD may interact with multiple aspects of the disease, including underlying abnormalities, patient age, type and results of surgical procedure, and age at surgery. Surgical scar and residual hemodynamic problems are important factors that increase the risk of arrhythmia. Acquired factors may also increase the risk of arrhythmias in $\mathrm{CHD}$. The mechanism of rhythm disturbances in CHD is multiform; they require substrates, triggers, and maintenance factors. Reentry is known as the most common mechanism of arrhythmias in CHD. Diagnosis should be based on all factors affecting arrhythmogenesis in CHD. A practical approach to rhythm disturbances could be helpful for clinicians to obtain proper diagnosis and treatment. A simple stepwise approach will be discussed, and an illustrative case will be shown, to demonstrate the application of this simple stepwise method to rhythm disturbances in CHD.

\section{Prevalence and relative risk of arrhythmias in CHD}

The prevalence of supraventricular and/or ventricular arrhythmias is recently reported to be $18 \%{ }^{1)}$. With the increasing number of grown-up CHD cases, rhythm disturbance has become more important in the cardiac management of CHD. Arrhythmias most likely occur at an advanced age.

The prevalence of late-onset atrial flutter or atrial fibrillation in atrial septal defect (ASD) increases progressively with aging, more so in patients who underwent surgery after 11 years of age and patients over the age of $40^{2-4)}$. Rhythm disturbances in ASD have much do to with longstanding volume overload on the right heart, compounded by tricuspid regurgitation, pulmonary arterial hypertension, and heart failure. However, the left atrial and pulmonary venous involvement is thought to be involved in the arrhythmogenesis of ASD because the success rate of maze operation for atrial fibrillation was higher than the modified rightsize maze procedure in restoring and maintaining sinus rhythm after ASD closure ${ }^{5)}$. The transcatheter closure of ASDs may possibly reduce the risk of atrial arrhythmia if done at a younger age, if treated at smaller defects, and because of the absence of surgical scars, which themselves may act as a reentrant circuit for arrhythmia. Transcatheter closure of ASD has been reported to have a low risk of late atrial arrhythmias in patients who underwent procedure at less than 55 years old ${ }^{(6)}$.

Ventricular tachycardia after repair of tetralogy of Fallot (TOF) can serve as a paradigm for postoperative ventricular tachycardia in the CHD population. Reentry is known to be the main mechanism of arrhythmia, which circulates around the scar or patch in the right ventricular outflow tract ${ }^{7}$. Long-lasting pressure overload of the right ventricle and long-standing hypoxemia could contribute to pathologic changes such as cardiomyocytic degeneration and interstitial fibrosis, which have been implicated in myocardial dysfunction and ventricular arrhythmias ${ }^{8)}$. The risk factors of ventricular tachycardia in repaired TOF are as follows: moderate or severe pulmonary regurgitation, history of sustained ventricular tachycardia, moderate or severe left ventricular dysfunction, prolonged QRS duration more than $180 \mathrm{~ms}$, and rapid change of QRS duration ${ }^{9-15}$. In patients with repaired TOF, sustained ventricular tachycardia and sudden cardiac death are reported to be $11.9 \%$ and $8.3 \%$, respectively, with incidence per decade of sudden death of $1.2-3.0 \%{ }^{16-19)}$. Pulmonary valve replacement reduces right ventricular size and stabilizes QRS duration; however, substantial reduction in the incidence of subsequent monomorphic ventricular tachycardia is controversial ${ }^{20,}$ ${ }^{21)}$. Although often less dramatic than ventricular arrhythmias in terms of hemodynamic complications, atrial arrhythmias are almost equally as frequent in repaired $\mathrm{TOF}^{9,22)}$. The risk of supraventricular tachycardia in repaired TOF is reported to be minimal until QRS duration becomes more than $160 \mathrm{~ms}^{23)}$.

In patients who underwent the Fontan procedure, preoperative and postoperative risk factors should be considered in dealing with rhythm disturbances. Preoperative risk factors include atrioventricular valve regurgitation, older age at operation, poor preoperative functional status, previous atrial septectomy, and preoperative atrial tachyarrhythmia ${ }^{24-26)}$. Postoperatively, surgeryrelated factors should be considered, such as pulmonary artery reconstruction, atriopulmonary anastomosis, early postoperative atrial tachyarrhythmia, and postoperative sinus node dysfunction. Efforts to decrease long-term complications such as arrhythmias have brought several modifications to the Fontan operation, with consequent reduction of incidence of arrhythmias ${ }^{27-29)}$.

Specific arrhythmias and associated defects can be divided into 2 parts: tachycardia and bradycardia. Supraventricular tachycardias occur in $30-50 \%$ of patients after atrial switch operation for complete transposition of the great arteries (TGA) ${ }^{30)}$. Intraatrial reentrant tachycardia (IART) is common in postoperative Mustard, Senning, and Fontan operations. Atrial fibrillation in mitral valve diseases, aortic stenosis, and unrepaired functional single ventricle may also occur. An accessory pathway is common in Ebstein anomaly and corrected TGA ${ }^{31,32)}$. The incidence of supraventricular tachycardias in Ebstein anomaly is reported to be $40-80 \%{ }^{33)}$. Twin atrioventricular (AV) node can be present in heterotaxy syndrome (right isomerism). In Fontan repair, 
supraventricular tachycardias commonly develop with an incidence of $30-60 \%{ }^{24,25,34)}$. The most common tachyarrhythmia in repaired TOF is supraventricular tachycardia, the incidence of which is reported to be up to $35 \%{ }^{16,33)}$. Ventricular tachycardia is well known in repaired TOF and congenital aortic stenosis. Even in repaired ASD or repaired VSD, late arrhythmia could occur with the incidence of 5-15\% in ASD and less than 2\% in VSD ${ }^{34,35)}$.

In bradycardia, sinoatrial node (SA) node dysfunction can be present in heterotaxy syndrome (left isomerism: polysplenia) or from damage in postoperative Mustard, Senning, and Fontan operations. The AV node can also be naturally blocked in corrected TGA and AV septal defect (AVSD), and can be damaged after surgical repair of ventricular septal defect (VSD), subaortic stenosis, and $\mathrm{AV}$ valve replacement.

The relative risk for specific arrhythmias in CHD depends on the underlying congenital heart defect (Table 1$)^{36)}$. Ventricular tachycardia or sudden cardiac death is much more common in TOF, aortic stenosis, and atrial switch-operated complete TGA. Scar-related atrial tachycardias can develop in almost all CHD cases with atrial scars, but are more common in atrial switchoperated complete TGA and Fontan-operated single ventricle. Accessory pathways are commonly noted in corrected TGA and Ebstein anomaly. Long after atria switch operation (Mustard or Senning operation) for complete TGA, IART and sinus node dysfunction are commonly noted. Fontan operation is known to have a high incidence of sinus node dysfunction. AV conduction abnormality is high in corrected TGA and AVSD.

\section{Clinical implication of cardiac conduction development in the congenital heart malformations}

occur during the development of the conduction system in the prenatal and/or postnatal period ${ }^{37)}$. During embryological development, sinus node and AV node form cardiac chambers. Errors in the control of cardiac development may lead to a heart with a mirror-image position, which is called situs inversus; abnormal location of sinus node and AV node, which is common in corrected TGA and AVSD; and dual or absent sinus node and atriovenricular node, which are common in atrial isomerism (asplenia or polysplenia). After completion of inflow and outflow of both ventricles, normal ventricular conduction system is also completed. Abnormal heart development could lead to an abnormal conduction system. The conduction system also changes with aging.

\section{Substrates for rhythm disturbances in CHD}

Substrates for rhythm disturbances can be investigated in terms of the subcomponents of the cardiac conduction system. The pacemaker component has a sinus node that could be injured congenitally or by surgery. In the slow impulse conduction component, atrial conduction abnormalities and AV node damage could develop. Twin AV node, abnormal location of AV node, and accessory pathway can also be present. In the rapid impulse conduction component, the His-Purkinje system can be damaged. These functional and anatomical abnormalities can be substrates for reentry arrhythmias. Accessory pathways and twin AV nodes are also related to arrhythmias (Table 2).

\section{Predisposing factors and acquired factors to arrhythmias in CHD}

The risk of arrhythmias in CHD is different from that in a structurally normal heart. Many predisposing and acquired factors

malformations should begin by understanding the events that

Table 1. Comparison of Relative Risk of Rhythm Disturbances in Congenital Heart Diseases

\begin{tabular}{|c|c|c|c|c|c|c|c|}
\hline & IART & AF & WPW & $\begin{array}{l}V T \\
\text { SCD }\end{array}$ & $\begin{array}{l}\text { Sinus node } \\
\text { dysfunction }\end{array}$ & $\begin{array}{c}\text { Spontaneous } \\
\text { AV Block }\end{array}$ & $\begin{array}{l}\text { Traumatic } \\
\text { AV Block }\end{array}$ \\
\hline VSD & + & & & & & & + \\
\hline ASD & + & + & & + & & & \\
\hline TOF & ++ & & & & & & \\
\hline AS & & + & & ++ & & & + \\
\hline Complete TGA (s/p atrial switch op) & +++ & & & $\begin{array}{l}++ \\
++\end{array}$ & +++ & & \\
\hline AVSD & + & & & ++ & & + & ++ \\
\hline SV s/p Fontan op & +++ & + & & & +++ & & \\
\hline Corrected TGA & + & & ++ & + & & ++ & +++ \\
\hline Ebstein anomaly & ++ & & +++ & + & & & \\
\hline
\end{tabular}

Abbreviations: AF, atrial fibrillation; WPW, Wolff-Parkinson-White syndrome; SCD, sudden cardiac death; VSD, ventricular septal defect; ASD, atrial septal defect; TOF, tetralogy of Fallot; AS, aortic stenosis; TGA, transposition of the great arteries; AVSD, atrioventricular septal defect; SV s/p Fontan op, single ventricle after the Fontan operation; +++, high risk; ++, moderate risk; and +, low risk; atrial switch op, Mustard or Senning operation

Adopted from Walsh EP. Circulation 2007;115:3224-34. 
Table 2. Substrates for Rhythm Disturbances in Congenital Heart Diseases

Pacemaker component
Sinus node damage
Slow impulse conduction component
Intraatrial or interatrial conduction delay
Congenital/acquired
AV node
damage (congenital/ acquired)
dual (twin) AV node/ abnormal location
Accessory pathways
Rapid impulse conduction components
His-Purkinje system damage
Congenital /acquired

are involved in the arrhythmogenesis. Genetic and anatomical predispositions, such as congenital anomaly, are the underlying factors of arrhythmias.

Hemodynamic changes by internal and external stressors, such as heart failure, ischemia, cyanosis, hypertension, and infarction, may act as substrates for arrhythmias. Surgical scar and residual problems are also involved. Subsequent structural and electrical remodeling could stabilize arrhythmia with the help of iatrogenic factors such as electrolytes and/or medications.

Acquired factors like aging, hypertension, diabetes, obesity, and others may play important roles in arrhythmogenesis in CHD. Many factors influence rhythm disturbances throughout lifetime. Hemodynamic conditions could be influenced not only by underlying anatomical defect but also by acquired valvular and ventricular dysfunction. Aging is a well-known contributing factor for arrhythmogenesis of atrial fibrillation ${ }^{38)}$. Aging can also affect the cardiovascular system of CHD patients ${ }^{39-41)}$. Other common lifetime problems are coronary heart disease, hypertension, diabetes, and obesity (Table 3).

\section{Practical approach to arrhythmia in CHD}

The availability of a simple method to diagnose rhythm disturbances in CHD is very helpful for the clinician. This stepwise approach to rhythm disturbances in $\mathrm{CHD}$ can be applied based on the basic understanding of the cardiac conduction system. Using the cardiac conduction system subcomponents as the basis, each step should evaluate several points encompassing anatomy, conduction, hemodynamic conditions, surgery, and acquired factors. First check point should be the pacemaker component, evaluating if the sinus node works properly at its normal location. The second step should be assessing the atrial conduction of slow impulse conduction component. Third, the AV node function in the slow impulse conduction component should
Table 3. Factors Influencing Arrhythmogenesis in Congenital Heart Diseases influencing

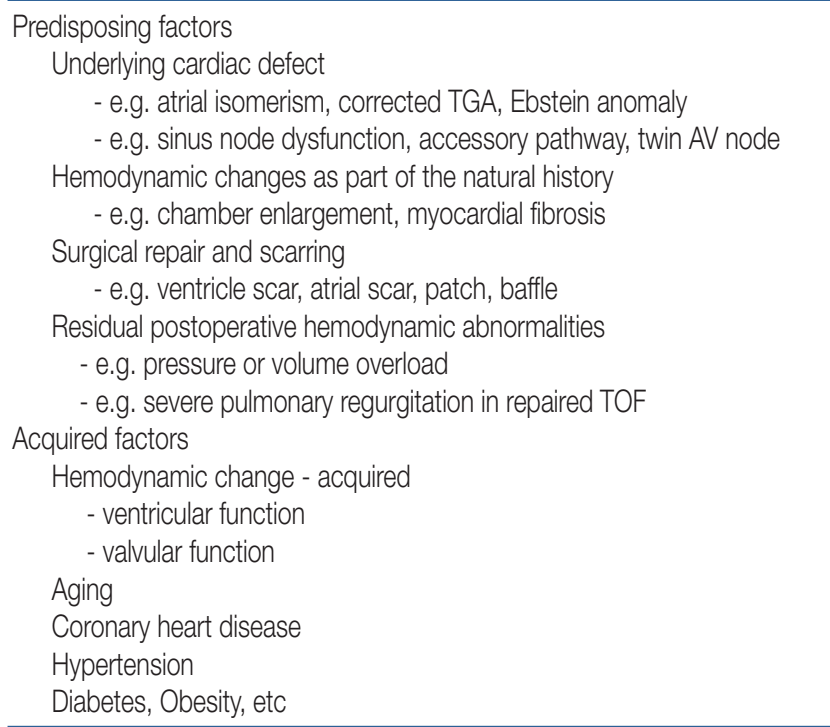

Table 4. Stepwise Approach to Arrhythmias according to Subcomponents of the Cardiac Conduction System

Step 1 - Pacemaker component

Sinus node node

Congenital - atrial isomerism

Acquired -surgical damage

Step 2 - Slow impulse conduction component

Atrium conduction delay

Congenital / acquired

Step 3 - Slow impulse conduction component

Atrioventricular(AV) node

Congenital / acquired

Accessory pathway

Corrected TGA, Ebstein anomaly

Dual (twin) AV node

Step 4 - Rapid impulse conduction component

His-Purkinje system damage

Congenital / acquired

Step 5 - Risk stratification

Atrial arrhythmia

Fontan procedure

Ventricular arrhythmia

s/p ventriculotomy

Risk of sudden cardiac death

Hemodynamic condition

Surgical correction?

be checked, looking at whether the accessory pathway or twin AV node is present. Fourth, the rapid impulse conduction component should be evaluated in terms of the status of the His-Purkinje system. Finally, the risk of arrhythmias and sudden cardiac death, hemodynamic status, and need for surgical intervention should be assessed (Table 4). 


\section{Clinical assessment of arrhythmias in CHD: an illustrative case of repaired TOF}

Fig. 1 shows an example of a stepwise approach to risk stratification of arrhythmias in CHD. This patient is an adult case with repaired TOF. By assessing predisposing and acquired factors, the total risk of arrhythmia in this repaired TOF case can be evaluated step by step, as follows:

Step 1: Underlying congenital defect is TOF without accessory pathway or conduction problems.

Step 2: Hemodynamic changes as part of the natural history of TOF are hypertrophy of the right ventricle and longstanding cyanosis.

Step 3: Surgical repair and scarring in repaired TOF are present in the right atrium and right ventricle.

Step 4: Residual postoperative hemodynamic abnormalities are severe pulmonary regurgitation and residual pulmonary stenosis.

Step 5: In addition to those factors, acquired factors also contribute to the development of arrhythmias.

Then, according to the subcomponents of cardiac conduction system, a stepwise approach to specific diagnosis of arrhythmias can be done as follows:

Step 1, for the pacemaker component: His SA node looks normal.

Step 2, for atrium of the slow conduction component: He has dilated atrium and surgical scar.

Step 3, for AV node of the slow conduction component: $\mathrm{He}$ has normal AV node conduction and low probability of accessory pathway.
Step 4, for the rapid conduction component: Left ventricle is normal in volume and function, but right ventricle is dilated with severe pulmonary regurgitation and surgical scar.

Step 5, for risk stratification: He has several risk factors, such as older age at initial repair, prolonged QRS duration of more than $180 \mathrm{~ms}$, and severe pulmonary regurgitation.

From the above information, we can conclude that this patient has high risk of atrial and ventricular arrhythmia and presumptive diagnosis of clinically significant tachycardia supported by history of palpitation. Finally, the decision for an approgriate treatment, whether the patient needs electrophysiologic study, should be made. The patient seems to need surgery for poor pulmonary valve function, causing severe RV volume load. Therefore, electrophysiology study and catheter ablation, if needed, should be performed before surgery. Concomitant arrhythmia surgery or ICD implantation may be recommended if ventricular tachycardia is documented.

\section{Schematic approach to electrophysiologic study and treatment of supraventricular tachycardia/ ventricular tachycardia in CHD}

The schematic approach to the electrophysiologic study with catheter ablation in supraventricular arrhythmias in CHD is shown in Fig. 2. For surpaventricular arrhythmias in CHD, the assessment of hemodynamic condition is very important. Medication may be the first line of treatment in some patients. Patients are divided into 5 groups: The first group is composed of patients who did not undergo surgery and do not need surgical

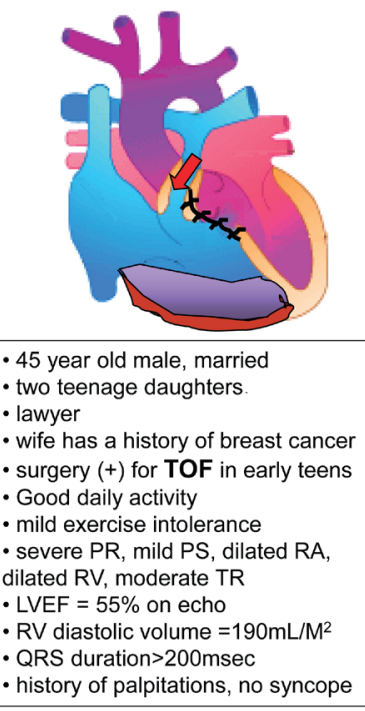

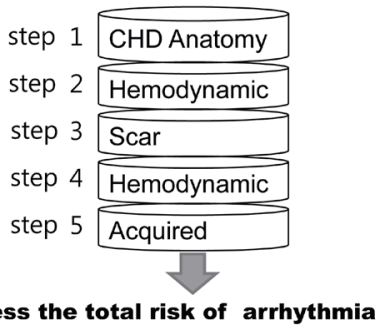

Assess the total risk of arrhythmia

step 1 Pacemaker component

step 2 Slow impulse conduction component-atrium

step $3 \longdiv { \text { Slow impulse conduction component-AV node } }$

step $4 \longdiv { \text { Rapid impulse conduction component } }$

step $5 \longdiv { \text { Risk stratification } }$

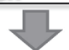

Approach to the specific diagnosis

Fig. 1. Example of a stepwise approach to arrhythmias in repaired tetralogy of Fallot. 


\section{Symptomatic Supraventricular Arrhythmias}

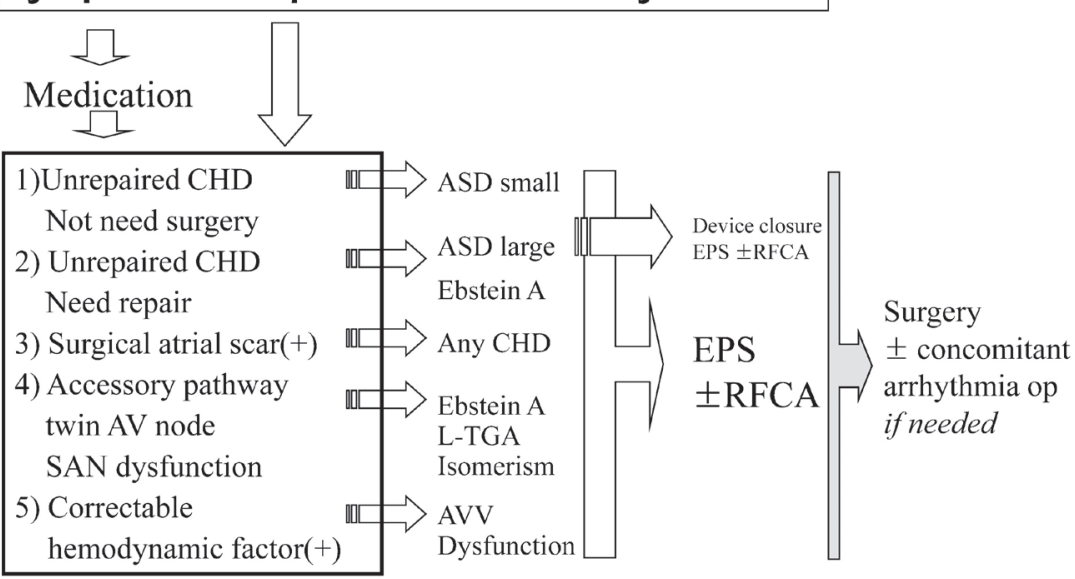

Fig. 2. Practical approach to the management of supraventricular tachycardias in congenital heart disease.

\section{Symptomatic Ventricular Arrhythmias}

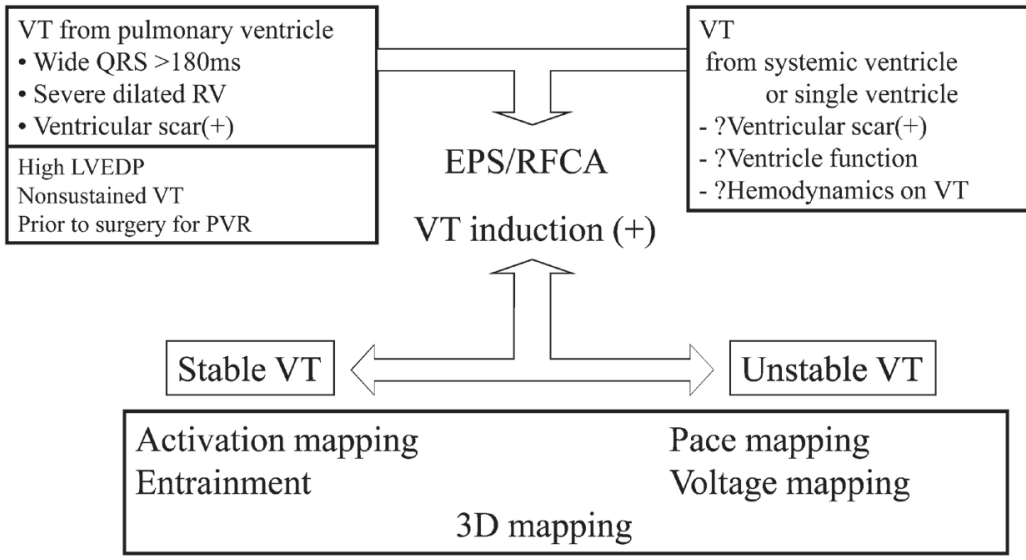

Successful RFCA ? ICD? Surgery?

Fig. 3. Practical approach to the management of ventricular tachycardia in congenital heart disease.

corrections such as small ASD. Electrophysiologic study with catheter ablation is recommended without closure of ASD. ASD closure is not indicated for the treatment of arrhythmia. The second group includes patients who did not undergo surgery but need repair of defects such as large ASD or Ebstein anomaly. In ASD, device closure can be done concomitantly with electrophysiologic study and catheter ablation. The third group includes patients who had open heart surgery and have atrial scars. The fourth group includes Ebstein anomaly, corrected TGA, and isomerism showing high incidence of accessory pathway, conduction abnormality, and twin AV node. Electrophysiologic study with catheter ablation is also recommended for these 2 groups. If there are any surgically correctable hemodynamic problems, electrophysiologic study with catheter ablation should be performed before surgery and concomitant arrhythmia surgery also should be considered.

Electrophysiologic study with catheter ablation is also performed for ventricular tachycardia occurring after repair of CHD (Fig. 2). In patients with RV scar after repair of $\mathrm{CHD}$ who have long QRS duration of more than $180 \mathrm{~ms}$, severe dilated RV, and history of ventriculotomy, additional risk factors such as high ventricle end diastolic pressure (LVEDP) and nonsustained ventricular tachycardia can prompt the electrophysiologic study and catheter ablation before the replacement of pulmonary valve. Ventricular tachycardia from systemic or single ventricle can develop in patients with CHD. However, there are no confirmed risk factors. Ventricular dysfunction and hemodynamic compromise during 
ventricular tachycardia are the most important factors in deciding invasive electrophysiologic intervention with/or without ICD implantation. Through electrophysiologic study, the necessity of ICD or concomitant arrhythmia surgery for the primary prevention of sudden cardiac death should be evaluated.

\section{Conclusion}

In the assessment of rhythm disturbances in CHD, predisposing and acquired factors should be evaluated, looking at the development of the conduction system in congenital heart malformations. A stepwise approach could help clinicians to easily obtain the proper diagnosis and suggest appropriate treatments. Correction of residual hemodynamic abnormalities may be critical in the treatment of arrhythmia in CHD. The electrophysiological assessment and management should be done with integrated care of the underlying heart defects and hemodynamic abnormalities.

For the growing population of CHD patients, future studies should focus on minimizing the potential substrates for rhythm disturbances and on finding early aggressive treatments. Prevention of other cardiovascular diseases related to aging, such as coronary artery disease, hypertension, and others, should also be emphasized.

\section{References}

1) van der Velde ET, Vriend JW, Mannens MM, Uiterwaal CS, Brand R, Mulder BJ. CONCOR, an initiative towards a national registry and DNA-bank of patients with congenital heart disease in the Netherlands: rationale, design, and first results. Eur J Epidemiol 2005;20:549-57.

2) Murphy JG, Gersh BJ, Mair DD, Fuster V, McGoon MD, Ilstrup $\mathrm{DM}$, et al. Long-term outcome in patients undergoing surgical repair of tetralogy of Fallot. N Engl J Med 1993;329:593-9.

3) Gatzoulis MA, Freeman MA, Siu SC, Webb GD, Harris L. Atrial arrhythmia after surgical closure of atrial septal defects in adults. N Engl J Med 1999;340:839-46.

4) Mantovan R, Gatzoulis MA, Pedrocco A, Ius P, Cavallini C, De Leo A, et al. Supraventricular arrhythmia before and after surgical closure of atrial septal defects: spectrum, prognosis and management. Europace 2003;5:133-8.

5) Kobayashi J, Yamamoto F, Nakano K, Sasako Y, Kitamura S, Kosakai Y. Maze procedure for atrial fibrillation associated with atrial septal defect. Circulation 1998;98(19 Suppl):II399-402.

6) Silversides CK, Siu SC, McLaughlin PR, Haberer KL, Webb GD, Benson L, et al. Symptomatic atrial arrhythmias and transcatheter closure of atrial septal defects in adult patients. Heart 2004;90:1194-8.

7) Zeppenfeld K, Schalij MJ, Bartelings MM, Tedrow UB, Koplan BA, Soejima K, et al. Catheter ablation of ventricular tachycardia after repair of congenital heart disease: electroanatomic identification of the critical right ventricular isthmus. Circulation 2007;116:2241-52.
8) Chowdhury UK, Sathia S, Ray R, Singh R, Pradeep KK, Venugopal P. Histopathology of the right ventricular outfl ow tract and its relationship to clinical outcomes and arrhythmias in patients with tetralogy of Fallot. J Thorac Cardiovasc Surg 2006;132:270-7.

9) Gatzoulis MA, Balaji S, Webber SA, Siu SC, Hokanson JS, Poile C, et al. Risk factors for arrhythmia and sudden death late after repair of tetralogy of Fallot: a multicentre study. Lancet 2000;356:975-81.

10) Gatzoulis MA, Till JA, Redington AN. Depolarization-repolarization inhomogeneity after repair of tetralogy of Fallot. The substrate for malignant ventricular tachycardia? Circulation 1997;95:401-04.

11) Berul CI, Hill SL, Geggel RL, Hijazi ZM, Marx GR, Rhodes J, et al. Electrocardiographic markers of late sudden death risk in postoperative tetralogy of Fallot children. J Cardiovasc Electrophysiol 1997;8:1349-56.

12) Gatzoulis MA, Till JA, Somerville J, Redington AN. Mechanoelectrical interaction in tetralogy of Fallot. QRS prolongation relates to right ventricular size and predicts malignant ventricular arrhythmias and sudden death. Circulation 1995;92:231-7.

13) Tateno $S$, Niwa K, Nakazawa $M$, Iwamoto $M$, Yokota $M$, Nagashima $M$, Echigo $S$, et al. Risk factors for arrhythmia and late death in patients with right ventricle to pulmonary artery conduit repair--Japanese multicenter study. Int J Cardiol 2006;106:373-81.

14) Uebing A, Gibson DG, Babu-Narayan SV, Diller GP, Dimopoulos K, Goktekin O, et al. Right ventricular mechanics and QRS duration in patients with repaired tetralogy of Fallot: implications of infundibular disease. Circulation 2007;116:1532-9.

15) Wijnmaalen AP, Schalij MJ, Bootsma M, Kies P, DE Roos A, Putter H, et al. Patients with scar-related right ventricular tachycardia: determinants of long-term outcome. J Cardiovasc Electrophysiol 2009;20:1119-27.

16) Nollert G, Fischlein T, Bouterwek S, Bohmer C, Klinner W, Reichart B. Long-term survival in patients with repair of tetralogy of Fallot: 36-year follow-up of 490 survivors of the first year after surgical repair. J Am Coll Cardiol 1997;30:1374-83

17) Silka MJ, Hardy BG, Menashe VD, Morris CD. A population-based prospective evaluation of risk of sudden cardiac death after operation for common congenital heart defects. J Am Coll Cardiol 1998;32:245-51.

18) Nørgaard MA, Lauridsen P, Helvind M, Pettersson G. Twenty-tothirty-seven-year follow-up after repair for Tetralogy of Fallot. Eur J Cardiothorac Surg 1999;16:125-30.

19) Therrien J, Webb G. Clinical update on adults with congenital heart disease. Lancet 2003;362:1305-13.

20) Therrien J, Siu SC, Harris L, Dore A, Niwa K, Janousek J, et al. Impact of pulmonary valve replacement on arrhythmia propensity late after repair of tetralogy of Fallot. Circulation 2001;103:2489-94.

21) Harrild DM, Berul CI, Cecchin F, Geva T, Gauvreau K, Pigula F, et al. Pulmonary valve replacement in tetralogy of Fallot: impact on survival and ventricular tachycardia. Circulation 2009;119:445-51.

22) Harrison DA, Siu SC, Hussain F, MacLoghlin CJ, Webb GD, Harris L. Sustained atrial arrhythmias in adults late after repair of tetralogy of Fallot. Am J Cardiol 2001;87:584-8.

23) Karamlou T, Silber I, Lao R, McCrindle BW, Harris L, Downar E, et al. Outcomes after late reoperation in patients with repaired tetralogy of Fallot: the impact of arrhythmia and arrhythmia surgery. Ann Thorac Surg 2006;81:1786-93.

24) Durongpisitkul K, Porter CJ, Cetta F, Offord KP, Slezak JM, Puga FJ, et al. Predictors of early- and late-onset supraventricular tachyarrhythmias after Fontan operation. Circulation 1998;98:1099-107. 
25) Gelatt M, Hamilton RM, McCrindle BW, Gow RM, Williams WG, Trusler GA, et al. Risk factors for atrial tachyarrhythmias after the Fontan operation J Am Coll Cardiol 1994;24:1735-41.

26) Fishberger SB, Wernovsky G, Gentles TL, Gauvreau K, Burnett J, Mayer JE Jr, et al. Factors that influence the development of atrial flutter after the Fontan operation. J Thorac Cardiovasc Surg 1997;113:80-6.

27) Stamm C, Friehs I, Ho SY, Moran AM, Jonas RA, del Nido PJ. Congenital supravalvar aortic stenosis: a simple lesion? Eur J Cardiothorac Surg 2001;19:195-202.

28) Sheikh AM, Tang AT, Roman K, Baig K, Mehta R, Morgan J, et al. The failing Fontan circulation: Successful conversion of atriopulmonary connections. J Thorac Cardiovasc Surg 2004;128:60-6.

29) Morales DL, Dibardino DJ, Braud BE, Fenrich AL, Heinle JS, Vaughn WK, et al. Salvaging the failing Fontan: Lateral tunnel versus extracardiac conduit. Ann Thorac Surg 2005;80:1445-52.

30) Gatzoulis MA, Walters J, McLaughlin PR, Merchant N, Webb GD, Liu P. Late arrhythmia in adults with the mustard procedure for transposition of great arteries: a surrogate marker for right ventricular dysfunction? Heart 2000;84:409-15.

31) Brown ML, Dearani JA, Danielson GK, Cetta F, Connolly HM, Warnes CA, et al. Functional status after operation for Ebstein anomaly: the Mayo Clinic experience. J Am Coll Cardiol 2008;52:460-6.

32) Watson H. Natural history of Ebstein's anomaly of tricuspid valve in childhood and adolescence. An international co-operative study of 505 cases. Br Heart J 1974;36:417-27.
33) Overgaard CB, Harrison DA, Siu SC, Williams WG, Webb GD, Harris L. Outcome of previous tricuspid valve operation and arrhythmias in adult patients with congenital heart disease. Ann Thorac Surg 1999;68:215863.

34) Monro JL, Alexiou C, Salmon AP, Keeton BR. Reoperations and survival after primary repair of congenital heart defects in children. J Thorac Cardiovasc Surg 2003;126:511-20.

35) Khairy P, Dore A, Talajic M, Dubuc M, Poirier N, Roy D, et al. Arrhythmias in adult congenital heart disease. Expert Rev Cardiovasc Ther 2006;4:83-95.

36) Walsh EP. Interventional electrophysiology in patients with congenital heart disease. Circulation 2007;115:3224-34.

37) Gittenberger-de Groot AC, Bartelings MM, Deruiter MC, Poelmann RE. Basics of cardiac development for the understanding of congenital heart malformations. Pediatr Res 2005;57:169-76.

38) Wongcharoen W, Chen YC, Chen YJ, Chen SY, Yeh HI, Lin CI, et al. Aging increases pulmonary veins arrhythmogenesis and susceptibility to calcium regulation agents. Heart Rhythm 2007;4:1338-49.

39) Aronow WS. Heart disease and aging. Med Clin North Am 2006;90: 849-62.

40) Casaclang-Verzosa G, Gersh BJ, Tsang TS. Structural and functional remodeling of the left atrium: clinical and therapeutic implications for atrial fibrillation. J Am Coll Cardiol 2008;51:1-11.

41) Pan NH; Tsao HM, Chang NC, Chen YJ, Chen SA. Aging dilates atrium and pulmonary veins: implications for the genesis of atrial fibrillation. Chest 2008;133:190-6. 